\title{
Effect of Vinylene Carbonate os Graphite Anode Cycling Efficiency
}

Paul Ridgway, Honghe Zheng, Gao Liu, Xiangun Song, Philip Ross, Vincent Battaglia Advanced Energy Technologies Department, Lawrence Berkeley National Laboratory, Berkeley, CA 94720

Vinylene Carbonate (VC) was added to the electrolyte in graphite-lithium half-cells. We report its effect on the coulombic efficiency (as capacity shift) of graphite electrodes under various formation cycling conditions. Cyclic voltammetry on glassy carbon showed that $\mathrm{VC}$ passivates the electrode against electrolyte reduction. The $\mathrm{dQ} / \mathrm{dV}$ plots of the first lithiation of the graphite suggest that VC alters the SE] layer, and that by varying the cell formation rate, the initial ratio of ethylene carbonate to $\mathrm{VC}$ in the SEI Jayer can be controlled. VC was found to decrease first cycle efficiency and reversible capacity (in ongoing cycling) when used to excess. However, experiments with VC additive used with various formation rates did not show any decrease in capacity shift.

\section{Introduction}

Carbonaceous materials, graphite formulations in particular, ane the current standard for battery anodes in electric vehicle lithium-ion batteries (1). To attain performance suitable for plug-in hybrid and all-electric vehicles, improvement in longevity of the graphite anode is needed. Electrolyte additives bave proven useful for this purpose. For example, vinylene carbonate $(\mathrm{VC})$ added to Propylene Carbonate/LiPF 6 electrolyte forms a Solvent-Electrolyte Interphase (SEI) layer on graphite anodes, preventing PC intercolation and reduction (and subsequent graphite exfoliaton) [2]. The addition of VC to EC-based $\mathrm{LiPF}_{6}$ electrolytes is reported to improve performance of graphite anodes by reducing irreversible capacity, suppressing gas formation, and improving cycling behavior [3-7].

An important aspect of anode performance is the effectiveness of the SEI layer in inhibiting the side reactions which form it. The continuation of these side reactions reduces cycling efficiency and consumes electrolyte which reduces the lifetime of the cell. We probe the effect of VC and various rates of formation on these continuing side reactions by measuring the "fractional capacity shift" (8). HydroQuébec's SNG-12 anode graphite was chosen for this study because its relatively high capacity shift is a performance problem in need of a solution.

In the results section, we begin by studying the effect of $\mathrm{VC}$ on the electrochemistry of glassy carbon in EC-based LiPF6 electrolyte. Then we determine a basis for choosing the concentration of VC in the cell. This leads to our measurements of the reversible capacity of graphite in lithium half-cells as a function of VC concentration, followed by an examination of the effect of $\mathrm{VC}$ on the $\mathrm{dQ} / \mathrm{dV}$ curves of the first lithiation of graphite. 
Finally we show the effect of formation rate and $\mathrm{VC}$ concentration on the fractional capacity shift.

\section{Experimental}

Electrode laminates with \$NG-12 graphite as the active material were provided by Hydro Québec, Inc (HQ). Coin cells were assembled in an argon atmosphere glove box (MBraun Unilab) with oxygen and water held below $5 \mathrm{ppm}$ and $-80^{\circ} \mathrm{C}$ dewpoint respectively. Physical characterization of the graphite, the laminate, and coin cell fabrication and cycling instrumentation details have been published previously ( $\$$ ). Vinylene carbonate (Sigma-Aldrich) and our electrolyte (1MLiPF ${ }_{6}$ in 1:2 EC:DEC) were used as received (9).

Cyclic voltammetry was done in the same argon atmosphere glove box, in a twocompartment glass cell with the working and reference electrode compartments separated by a glass frit, using a EG\&G PAR 273A. Potentiostat. The reference electrode was $\mathrm{Li}$ foil and the working electrode was glassy carbon (10).

\section{Results}

Cyclic voltammetry of glassy carbon in our electrolyte, without VC and with $5 \% \mathrm{VC}$ are shown in Figure1a and 1b respectively. Both plots show two cycles between the initial OCV of the clean electrode, and a negative limit of $0.25 \mathrm{~V}$ vs. Li. The first cycle was a slow $(0.2 \mathrm{mV} / \mathrm{s})$ formation scan. The second cycle was done at $2 \mathrm{mV} / \mathrm{s}$. The reduction current on the second negative scan with $5 \%$ VC was less than $25 \%$ of the current in the second scan without VC. Thus the presence of VC increased passivation of the glassy carbon to reduction of the solvent mixture. This suggests that VC might decrease coulombic inefficiency due to electrolyte solvent reduction in the cycling of graphite electrodes.
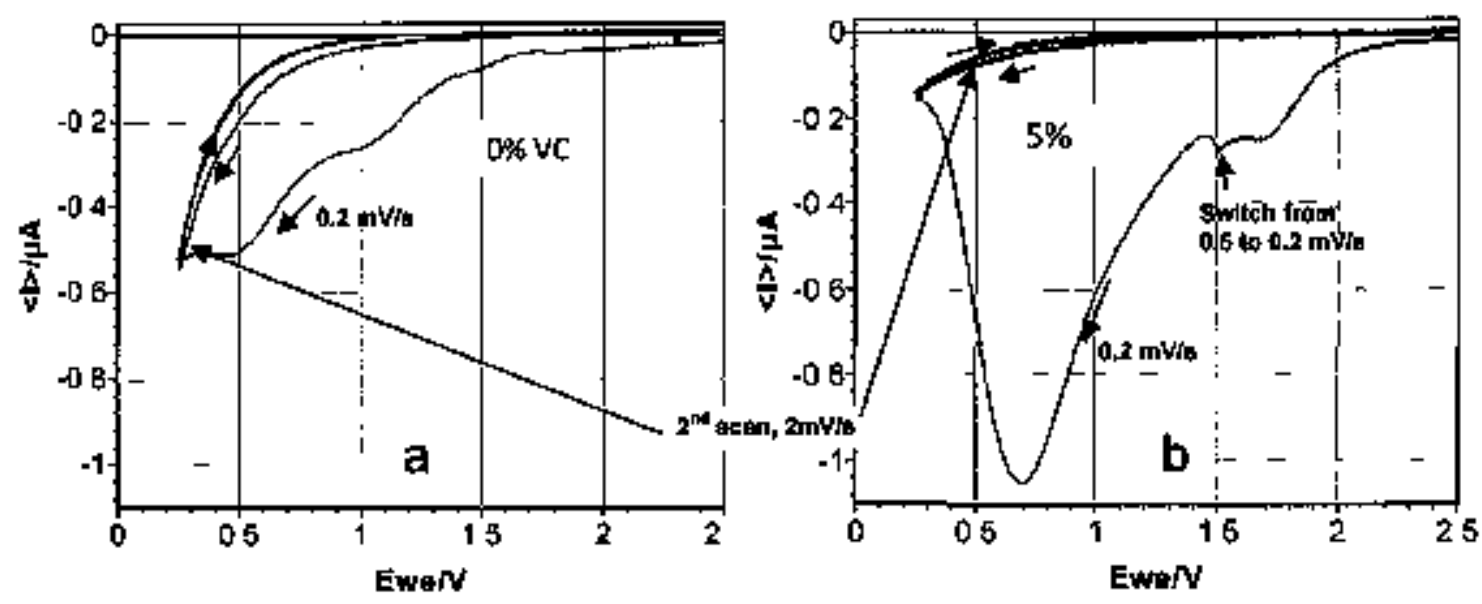

Figure 1. Cyclic voltammetry of glassy carbon in 1:2 EC:DEC, $1 \mathrm{M} \mathrm{LiPF} 6$ without VC (a) and with $5 \% \mathrm{VC}(\mathrm{b})$. 
Having decided, based on the CV data in Figure 1, to test the effect of VC on graphite anodes in coin cells with lithium counter electrodes, we considered a rationale for choosing the $\mathrm{VC}$ concentrations to test. Previous experiments with SNG-12 graphite in coin cells with this electrolyte versus lithium, gave first cycle coulombic efficiencies of $\sim 84 \%$ (8). Assuming that capacity loss (, $2 \mathrm{mAh}$ ) was due to electrolyte reduction at two electrons per molecule, $\sim 4 \mu \mathrm{mol}$ of solvent was reduced. To add that amount of VC to our coin cells we prepared electrolyte solution with $0.5 \% \mathrm{VC}$. To test the effect of additional VC, we also cycled cells with 2.5 and $15 \%$ VC, as well as $0 \% \mathrm{VC}$. The first cycle irreversible capacity and efficiency tabulated in Table 1 show that $0.5 \% \mathrm{VC}$ has no effect on these performance measures, but the higher $\mathrm{VC}$ concentrations degrade cell performance by these metrics.

\begin{tabular}{|l|r|r|r|r|r|r|}
\hline cell & VC wt\% & VC initial & Cyc1 irrev & Elyte consumed & \multicolumn{2}{l|}{ Cyc1 eff } \\
\hline$\#$ & & (umol) & cap(mAh) & 0 2e-(umol) & (\%) \\
\hline $0 \mathrm{a}$ & 0 & & 0.20 & 3.8 & 83.6 \\
\hline $0 \mathrm{~b}$ & 0 & & 0.20 & 3.8 & 83.7 \\
\hline $0.5 \mathrm{a}$ & 0.5 & 3.5 & 0.21 & 3.9 & 82.1 \\
\hline $0.5 \mathrm{~b}$ & 0.5 & 3.5 & 0.19 & 3.6 & 82.5 \\
\hline $2.5 \mathrm{a}$ & 2.5 & 17.4 & 0.25 & 4.7 & 79.7 \\
\hline $2.5 \mathrm{~b}$ & 2.5 & 17.4 & 0.19 & 3.5 & 80.6 \\
\hline $15 \mathrm{a}$ & 15 & 104.6 & 0.24 & 4.5 & 61.6 \\
\hline $15 \mathrm{~b}$ & 15 & 104.6 & 0.24 & 4.4 & 66.1 \\
\hline
\end{tabular}

Table 1. First cycle performance of sng12 graphite- $\mathrm{Li}$ coin cells $\left(30^{\circ} \mathrm{C}\right)$

The reversible capacities of the first twelve cycles of these cells, plotted in Figure 2, also show no deleterious effect with $0.5 \% \mathrm{VC}$, but performance by this measure decreases at the higher VC concentrations tested. 


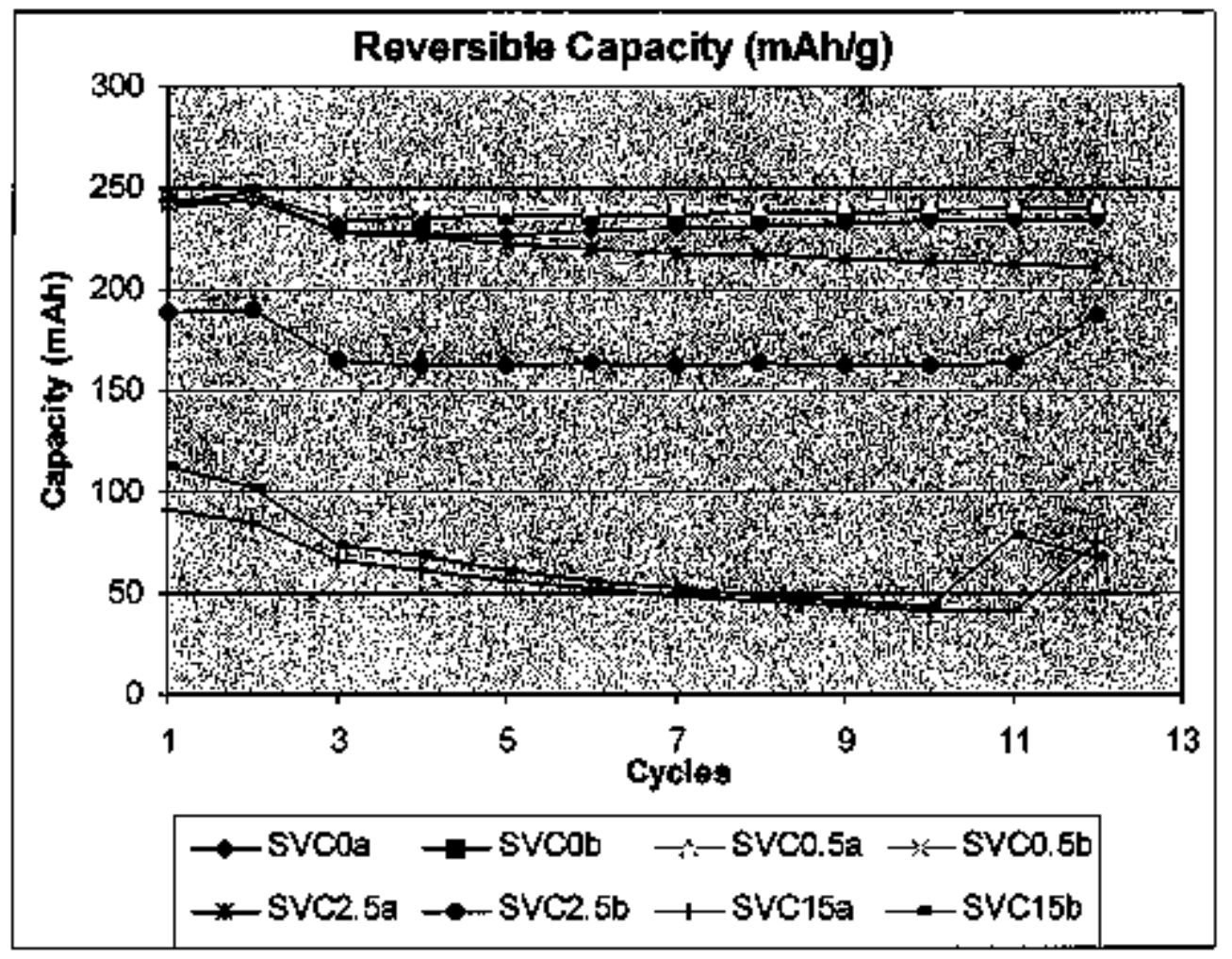

Figure 2. Reversible capacities vs. cycle of cells with $0 \% \mathrm{VC}$ (blue), $0.5 \% \mathrm{VC}$ (yellow), $2.5 \%$ (red), and $15 \% \mathrm{VC}$ (green).

The fractional capacity shift (the per-cycle ratio of irreversible to reversible capacity) of these cells is shown in Figure 3. Contrary to our expectation, VC had no effect on the capacity shift in any of the concentrations tested. 


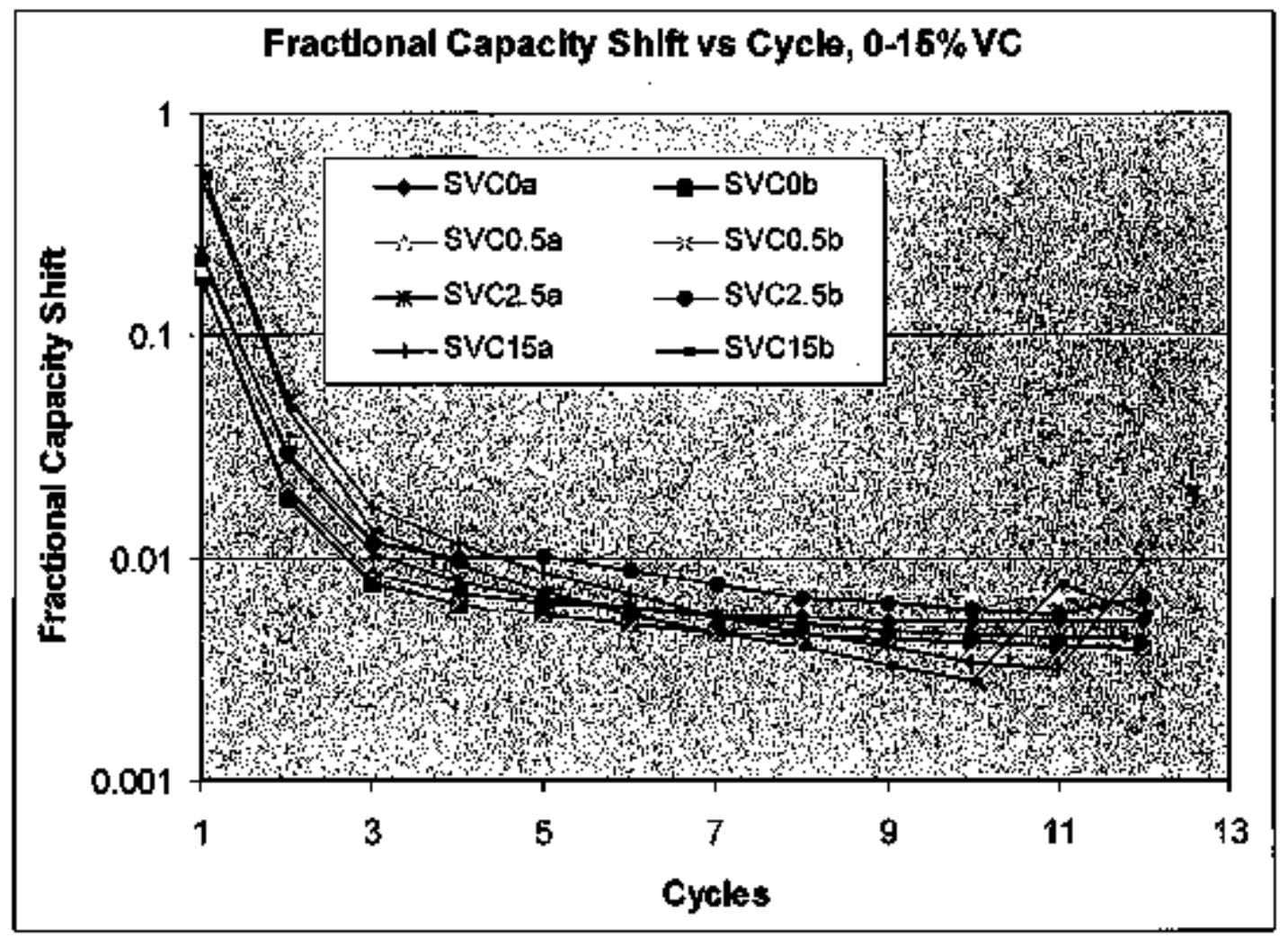

Figure 3. The fractional capacity shift vs, cycle of cells with $0 \% \mathrm{VC}$ (blue), $0.5 \% \mathrm{VC}$ (yellow), 2.5\%(red), and 15\% VC(green).

We then studied the dQ/dV curves of the first formation charge for these cells, which are shown in Figure 4. They indicate that as little as $0.5 \%$ VC reduces on the graphite electrode at $0.8 \mathrm{~V}$ vs $\mathrm{Li}$ and suppresses the initial EC reduction which occurs in the absence of $\mathrm{VC}$ at $0.7 \mathrm{~V}$. This suggests that varying the formation rate, in particular making it very slow, would allow selective reduction of $\mathrm{VC}$ during the first cycle formation, which might increase electrode passivation to electrolyte reduction, as it had on glassy carbon as shown in Figure 1.

The capacity shift vs. cycle number for cells with $0,0.5$ and $2 \% \mathrm{VC}$ at formation rates of $\mathrm{C} / 50, \mathrm{C} / 100$ and $\mathrm{C} / 150$ are compared with cells cycled without $\mathrm{VC}$ at our standard rate of $\mathrm{C} / 24$ are shown in Figure 5. Unfortunately, only one cell (formed at $\mathrm{C} / 150$, with $2 \% \mathrm{VC}$ ) showed a lower capacity shift than obtained at $\mathrm{C} / 24$ without $\mathrm{VC}$, and it was not repeatable. 


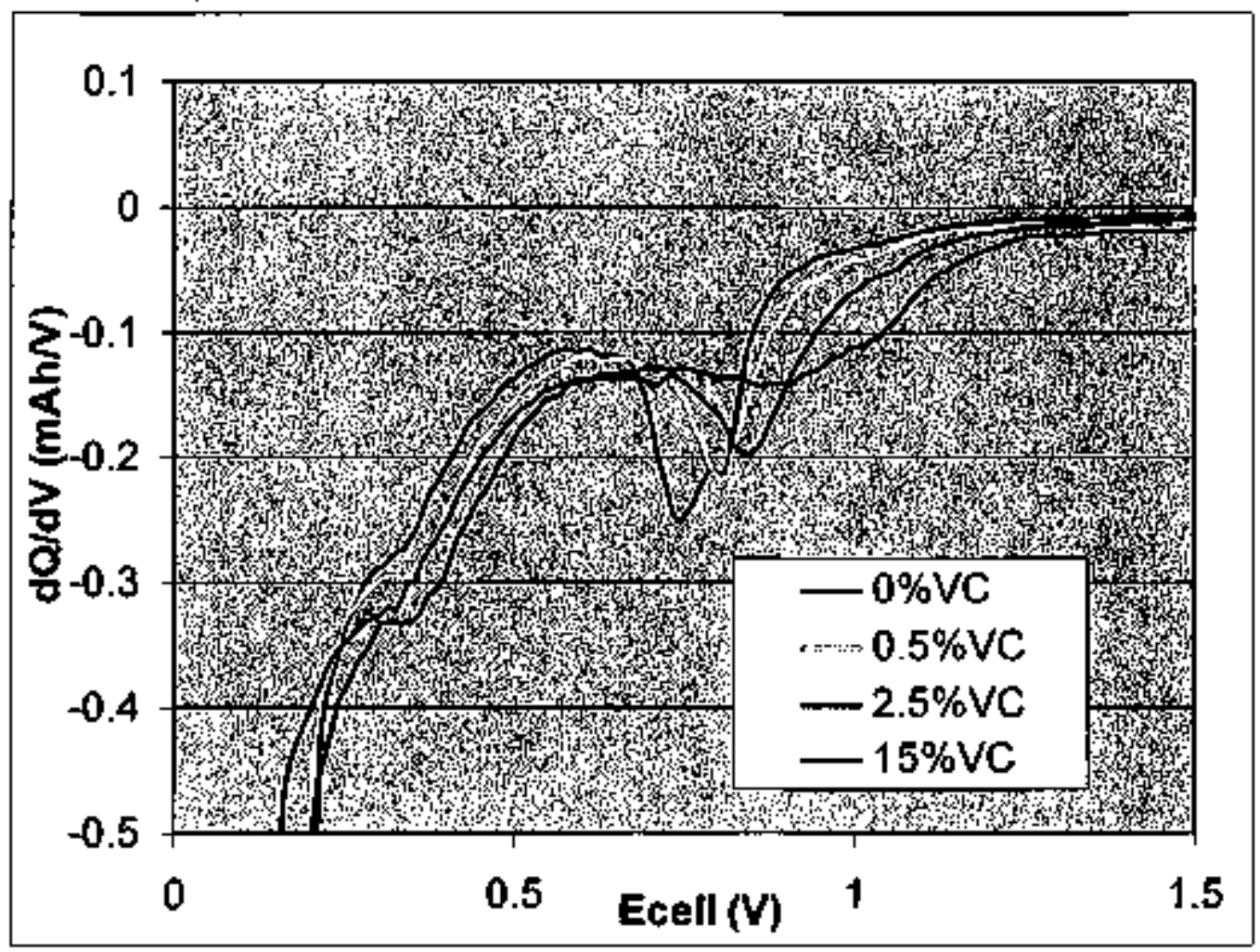

Figure 4. dQ/dV: SNG graphite vs. Li foil, I:2 EC+DEC, LMLiPF6, $0-15 \%$ VC, 1rst Charge, 2325 Coin cells, $\mathrm{I}=\mathrm{C} / 24$

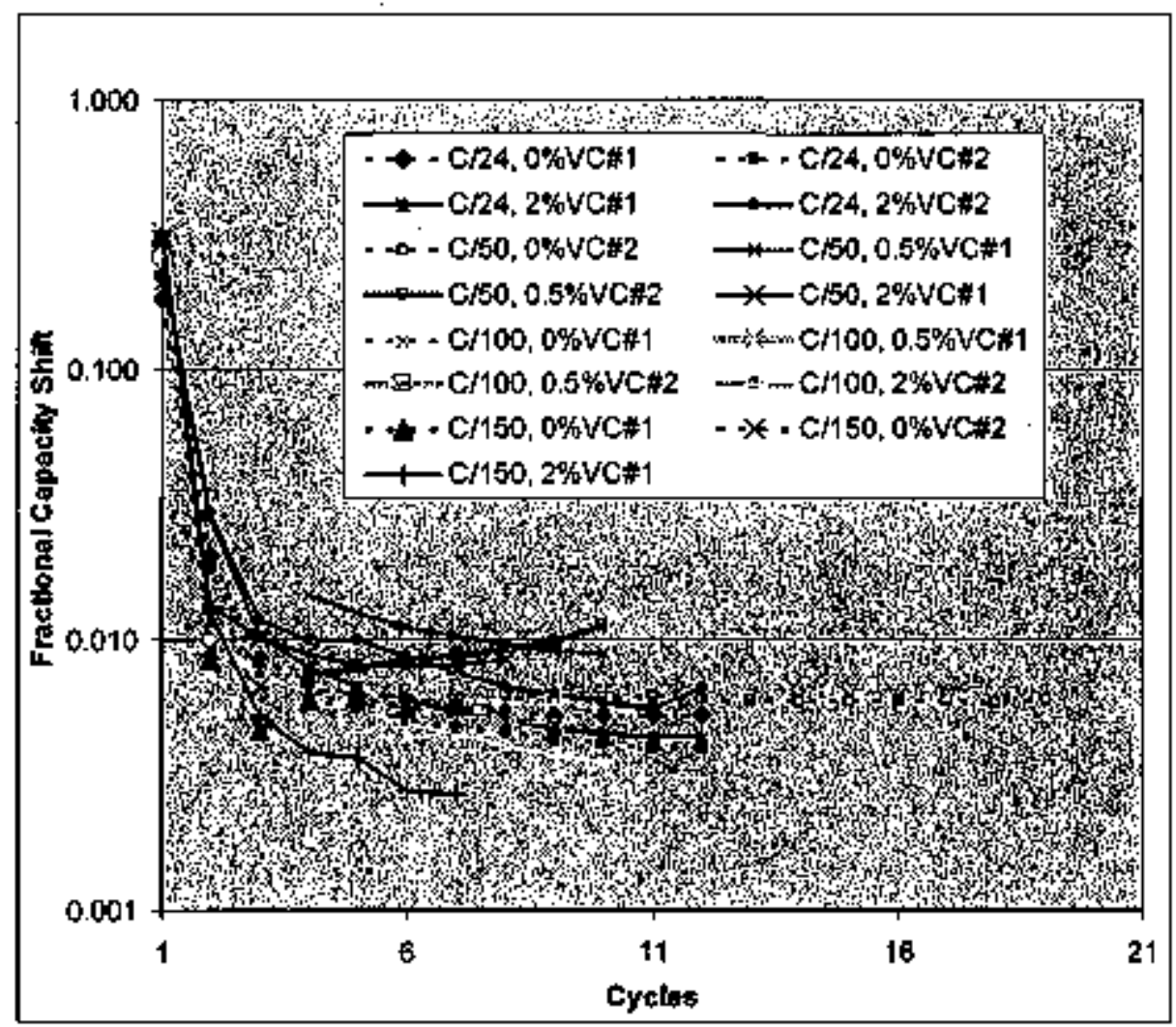

Figure 5. Capacity shift for cells formed at $\mathrm{C} / 24, \mathrm{C} / 50, \mathrm{C} / 100$ and $\mathrm{C} / 150$ with, $0,0.5$ and $2 \%$ VC. 


\section{Summary}

Though cyclic voltammetry experiments showed that VC increases passivation of glassy carbon with respect to $\mathrm{EC} / \mathrm{DEC}$ electrolyte solvent reduction, and $\mathrm{dQ} / \mathrm{dV}$ curves of first cycle lithiation of graphite indicate that it is possible to preferentially reduce of VC on graphite by using low first-lithiation electrode formation rates, no reproducible effect of VC and/or formation rate on capacity shifi was found.

\section{Acknowledgments}

This research was funded by the Assistant Secretary for Energy Efficiency, Office of Vehicle Technologies of the U.S. Department of Energy as part of the BATT program, under contract no. DE-ACO2-05CH1 1231.

\section{References}

1. T. Takamara and R. J. Brodd, in New Carbon Based Materials for Electrochemical Energy Storage Systems, I.V. Barsukov, et al. Editors, 157-169.0 2006 Springer. Printed in the Netherlands.

2. K, Abe, K. Miyoshi, et. al. J. Power Sources 184449 (2008).

3. D. Aurbach, K. Gamolsky, et.al. Electrochim. Acta 471423 (2002).

4. H. Ota, Y. Sakata, et.al. J. Electrochem. Soc. 151 Al659 (2004).

5. S.S. Zhang, J. Power Sources 1621379 (2006).

6. D.P. Abraham et al. Journal of Power Sources 180612 (2008).

7. M. Itagaki etal. Electrochim Acta 511629 (2006).

8. P. Ridgway, H. Zheng, et.al.,Electrochemical Sociefy Transactions, 13 (19) 1 (2008)

9. LIPF $_{6}$ and solvent purchased premixed from Ferro Corporation, 7500 East Pleasant Valley Rd, Independence OH 44131 , USA. Vinylene carbonate from Aldrich was stabilized with $<2 \%$ BHT

10. Working Electrode: $3 \mathrm{~mm}$ dia glassy carbon, Bio-Analytical Systems 